\title{
Acute Tubulointerstitial Nephritis Associated with Infliximab in a Patient with Crohn's Disease
}

\author{
Mineto Ota ${ }^{1}$, Hideyuki Iwai ${ }^{1}$, Kaori Imai ${ }^{1,2}$, Mari Kamiya ${ }^{1}$, Yoko Yoshihashi-Nakazato ${ }^{1}$, \\ Nobuyuki Miyasaka $^{1}$ and Hitoshi Kohsaka ${ }^{1}$
}

\begin{abstract}
We report the findings of a 46-year-old man, who presented with fever and renal dysfunction while undergoing treatment for Crohn's disease with infliximab (IFX). Remittent fever and renal dysfunction with urinary casts developed and lasted for 3 weeks without deterioration of Crohn's disease. Renal biopsy revealed acute tubulointerstitial nephritis (ATIN). After the discontinuation of IFX, his fever and renal abnormalities resolved. We herein report the first known case of ATIN associated with IFX.
\end{abstract}

Key words: acute tubulointerstitial nephritis, Crohn's disease, infliximab

(Intern Med 55: 1367-1370, 2016)

(DOI: 10.2169/internalmedicine.55.5834)

\section{Introduction}

Tumor necrosis factor (TNF)- $\alpha$ is a pro-inflammatory cytokine implicated in the pathogenesis of various inflammatory diseases. TNF- $\alpha$ inhibitors are biologic response modifiers, which lead to significantly improved functional outcomes in patients with rheumatoid arthritis (RA), Crohn's disease (CD), ulcerative colitis, Behçet's disease, psoriasis, and spinal arthropathy. Although infection, infusion reactions and de novo induction of autoimmunity have been reported as adverse effects, renal manifestations have only rarely been reported. We herein report a patient with $\mathrm{CD}$, who developed acute tubulointerstitial nephritis (ATIN) attributable to infliximab (IFX).

\section{Case Report}

A 46-year-old man had a 23-year history of $\mathrm{CD}$, which began with abdominal pain and diarrhea in 1989. He was treated with prednisolone, salazosulfapyridine and mesalazine, and thereafter went into remission. His bowel disease flared up in 2003, and the symptoms were successfully suppressed with the administration of IFX $6 \mathrm{mg} / \mathrm{kg}$ every 6 weeks.
In March 2012, the disease flared up again and was controlled with an increased dose of IFX $(10 \mathrm{mg} / \mathrm{kg})$ and the addition of mercaptoprine $(20 \mathrm{mg} /$ day $)$. Five months later, a remittent fever of up to 39 degrees Celsius developed and persisted for 3 weeks with no gastrointestinal or respiratory symptoms. Levofloxacin was orally administered for 7 days without any improvement. He was therefore admitted to our hospital for further evaluation.

Physical examination revealed no abnormalities in the abdominal signs, skin, joints, and ocular and neurological findings. Urinalyses revealed hematuria with 50-99 red blood cells/high-power field (HPF), 20-29 white blood cells/HPF, red blood cell casts and protein excretion $0.2 \mathrm{~g} / \mathrm{day}$, although no abnormality in the urinalyses had ever previously been observed until then. No abnormalities in the complete blood count, including the eosinophil count, were observed. $\mathrm{N}$-acetyl- $\beta$-D-glucosaminidase (NAG) and $\beta_{2}$-microglobulin in the urine were elevated to $44.7 \mathrm{U} / \mathrm{L}$ (reference range, 0.7 $11.2 \mathrm{U} / \mathrm{L}$ ) and $1,688 \mu \mathrm{g} / \mathrm{L}$ (reference range, $<200 \mu \mathrm{g} / \mathrm{L}$ ), respectively. After the onset of fever, serum creatinine $(\mathrm{sCr})$ increased from baseline $(0.85 \mathrm{mg} / \mathrm{dL})$ to $1.02 \mathrm{mg} / \mathrm{dL}$ before the administration of levofloxacin (LVFX) (Fig. 1).

C-reactive protein (CRP) was elevated to $11.2 \mathrm{mg} / \mathrm{dL}$. The immunoglobulin (Ig) G level was elevated to $1,837 \mathrm{mg} / \mathrm{dL}$ while the IgG4 level stayed normal $(30.2 \mathrm{mg} / \mathrm{dL})$. The com-

\footnotetext{
${ }^{1}$ Department of Rheumatology, Graduate School of Medical and Dental Sciences, Tokyo Medical and Dental University (TMDU), Japan and ${ }^{2}$ Department of Pharmacovigilance, Graduate School of Medical and Dental Sciences, Tokyo Medical and Dental University (TMDU), Japan Received for publication May 26, 2015; Accepted for publication August 10, 2015 Correspondence to Dr. Hitoshi Kohsaka, kohsaka.rheu@tmd.ac.jp
} 


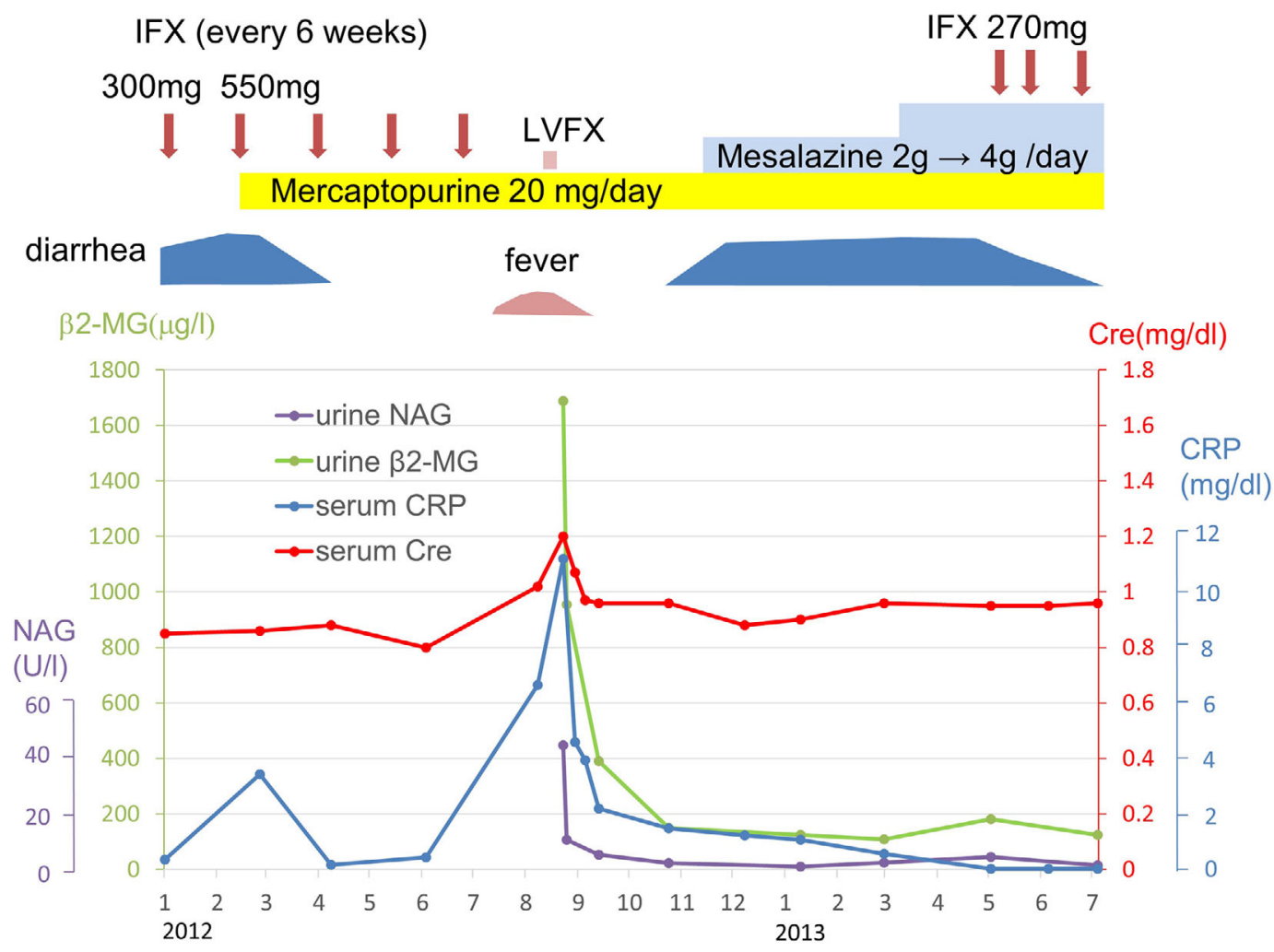

Figure 1. Clinical course. Cre: creatinine, CRP: C-reactive protein, IFX: infliximab, LVFX: levofloxacin, NAG: $N$-acetyl- $\beta$-D-glucosaminidase, $\beta_{2}$-MG: $\beta_{2}$-microglobulin

plement activity was slightly elevated (CH50 $74 \mathrm{U} / \mathrm{mL})$. Serological tests for antinuclear antibodies, anti-double stranded-DNA antibody and anti-neutrophil cytoplasmic autoantibodies were negative. A blood culture and urine culture including acid-fast bacillus were negative. A serum cytomegalovirus antigenemia assay, PCR analysis of herpes simplex virus, Epstein-Barr virus and parvovirus B19, and HBs antigen, anti-HCV antibody, anti-HIV antibody were all negative. Serum $\beta$-D glucan was negative. An abdominal computed tomographic scan revealed an enlargement of the bilateral kidneys. Colonoscopy revealed slight edema and mucosal erosion of the colon.

We performed percutaneous renal biopsy on day 16 of the admission (Fig. 2). The microsections contained 20 glomeruli. Two of them were globally sclerotic while the rest were intact. Mononuclear cells, especially CD3 positive cells, and neutrophils infiltrated patchily in the interstitium and between the tubular epithelial cells. The destruction of the tubular basement membranes was observed. No granulomas in the interstitium or the vasculature abnormalities were found. No deposition of IgG, IgG4 or C3 was observed in the tubular basement membrane. No loss of CD34 positive vascular endothelial cells in the peritubular capillaries was observed. All these findings implicated no involvement of peritubular capillary vasculitis. The pathological diagnosis was ATIN.

As his fever resolved gradually with an improvement in the renal function after the cessation of IFX, we followed up without the cessation of mercaptopurine (Fig. 1). He did not take any other drugs, including non-steroid antiinflammatory drugs, before the onset of ATIN. Levofloxacin was started after the renal dysfunction appeared. One month later, creatinine clearance improved from 65.8 to $85.16 \mathrm{~mL} /$ minute. Two months later, the CRP level and $\mathrm{sCr}$ went down to $1.48 \mathrm{mg} / \mathrm{dL}$ and $0.96 \mathrm{mg} / \mathrm{dL}$ respectively. NAG and $\beta_{2}$-microglobulin in the urine returned to a normal level (2.3 $\mathrm{U} / \mathrm{L}$ and $149 \mu \mathrm{g} / \mathrm{L}$ ) with normal urinalyses. Four months later, he developed frequent diarrhea because of an exacerbation of $\mathrm{CD}$, without any recurrence of renal abnormalities. We thus concluded that the ATIN in this case was attributable to IFX.

Though he was treated with mesalazine in addition to mercaptopurine, diarrhea and abdominal pain persisted. He declined the subcutaneous injection of adalimumab, the other TNF- $\alpha$ inhibitor approved for CD in Japan. As IFX 6 $\mathrm{mg} / \mathrm{kg}$ had been used without renal impairment for a long time, we tried IFX $5 \mathrm{mg} / \mathrm{kg}$ after eight months cessation, with a loading regimen at weeks 0,2 and 6 and thereafter every eight weeks. He has thus achieved remission again, which persists until now (for 2 years) without any renal impairment.

\section{Discussion}

This is the first report on IFX inducing ATIN. TNF- $\alpha$ inhibitors can induce autoimmune diseases including systemic lupus erythematosus (SLE), vasculitis, sarcoidosis, and inflammatory myopathies (1). As for renal disorders, glomeru- 


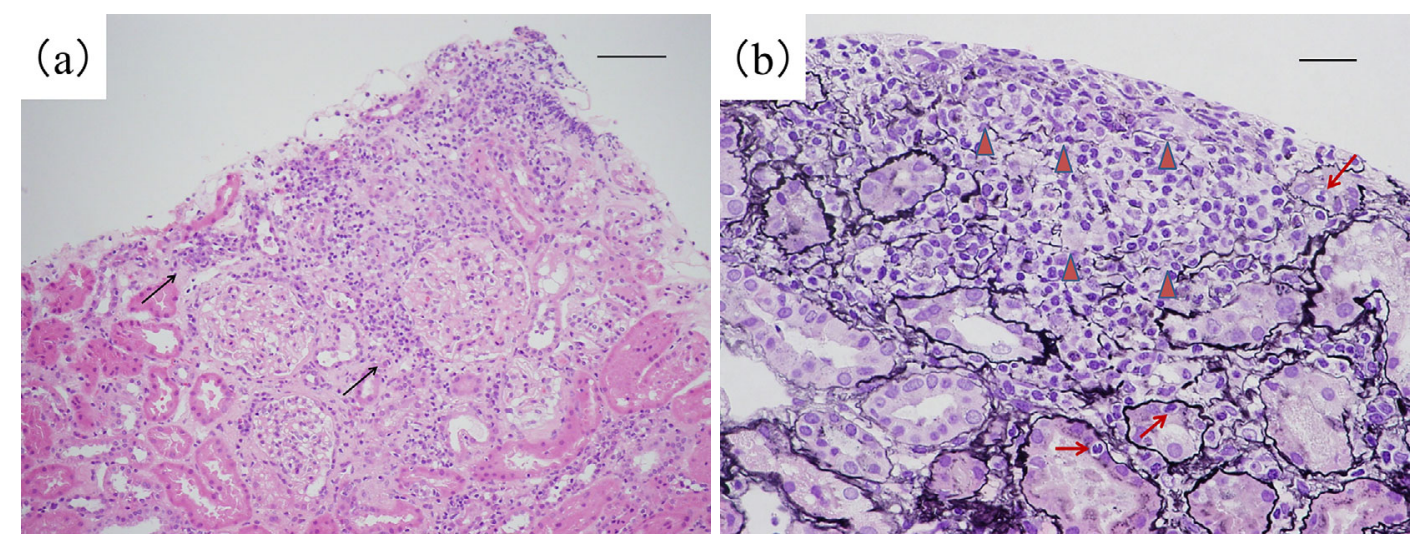

Figure 2. (a) Light microscopy of the renal biopsy specimen (Periodic acid-Schiff stain). Patchy interstitial infiltration of mononuclear cells and neutrophils (arrows), most of which are $\mathrm{CD3}^{+}$cells according to the immunohistochemical analyses (not shown), are seen. No granulomas or vascular changes are seen. The interstitium has no fibrotic changes, suggesting acute lesions. Bar=50 $\mu \mathrm{m}$. (b) Light microscopy of the renal biopsy (Periodic acid-Methenamine silver stain). Mononuclear cells and neutrophils between tubular epithelial cells (arrows), and the destruction of the tubular basement membranes (arrowheads) are seen. Bar $=20 \mu \mathrm{m}$.

lonephritis in TNF- $\alpha$ inhibitor-induced SLE $(2,3)$, ANCAassociated vasculitis $(2,4,5)$, and $\operatorname{IgA}$ vasculitis $(4,6)$ have been reported. There are only two reported cases with ATIN: an ankylosing spondylitis patient with granulomatous tubulointerstitial nephritis accompanying adalimumab-induced sarcoidosis (7) and a RA patient with tubulointerstitial nephritis under treatment with etanercept, which did not induce any other autoimmune abnormalities (8). We herein report a case with CD who developed IFX-induced ATIN. The three cases of ATIN had different underlying diseases treated with different kinds of TNF- $\alpha$ inhibitors.

Tubulointerstitial nephritis (TIN) occurs rarely as an extraintestinal manifestation of $\mathrm{CD}(9,10)$. Previously reported cases developed TIN during an exacerbation of CD (9). Since the renal dysfunction in the present case improved after the cessation of IFX without any altered CD activity, we concluded that ATIN was not attributable to CD. In addition, LVFX was also not considered to be responsible for ATIN because the fever and renal dysfunction preceded its administration. Although some viral infections may cause tubulointerstitial nephritis, all the viruses we examined were negative.

The reason why IFX had been well tolerated for 9 years before appearance of ATIN is not clear. Although calcineurin inhibitors can damage the kidneys after long time use, they induce chronic pathological changes (11). According to the acute-type histological damage observed in the kidney of the present case, it is unlikely that the long time use of IFX induced ATIN. We readministered IFX, because $25-50 \%$ of the reported cases of TNF- $\alpha$ inhibitors-associated autoimmune diseases could be rechallenged with the offending drugs without either a recurrence or worsening of symptoms $(1,3,12)$. The low dose rechallenge of IFX did not induce renal impairment. Though the serum peak concentration of IFX increases dose-dependently (13), the serum peak concentration of IFX during the loading phase is not reported to be higher than during the maintenance phase (14). Therefore, the increase in IFX might have played a key role in inducing ATIN.

Korsten et al. hypothesized that interferon (IFN)- $\alpha$ should be increased by TNF- $\alpha$ inhibitors. It could induce autoimmune diseases such as SLE with nephritis (7). Treatment with Etanercept, a TNF- $\alpha$ inhibitor, exacerbates the IFN- $\alpha$ overexpression of cultured human peripheral blood mononuclear cells in a dose-dependent manner (15). IFN- $\alpha$ injection was reported to induce glomerulonephritis and interstitial nephritis in a mouse model of SLE (16). Some predispositions, such as genetic polymorphisms associated with autoimmune disease and increased IFN- $\alpha$ with IFX, might have led to ATIN in this case.

Although ATIN due to the administration of TNF- $\alpha$ inhibitors is rare, we should be aware of this possibility and carefully monitor patients for this potential complication.

\section{Author's disclosure of potential Conflicts of Interest (COI).}

Hitoshi Kohsaka: Employment, Chugai Pharmaceutical and Teijin Pharma; Honoraria, Chugai Pharmaceutical, Mitsubishi Tanabe Pharma and Ono Pharma ceutical; Research funding, BristolMyers Squibb, Eisai, Mitsubishi Tanabe Pharma and Takeda Pharmaceutical. Nobuyuki Miyasaka: Research funding, AbbVie, Mitsubishi Tanabe Pharma, and Takeda Pharmaceutical.

\section{References}

1. Ramos-Casals M, Brito-Zerón P, Soto MJ, Cuadrado MJ, Khamashta MA. Autoimmune diseases induced by TNF-targeted therapies. Best Pract Res Clin Rheumatol 22: 847-861, 2008.

2. Stokes MB, Foster K, Markowitz GS, et al. Development of glomerulonephritis during anti-TNF- $\alpha$ therapy for rheumatoid arthritis. Nephrol Dial Transplant 20: 1400-1406, 2005.

3. Costa MF, Said NR, Zimmermann B. Drug-induced lupus due to 
anti-tumor necrosis factor $\alpha$ agents. Semin Arthritis Rheum 37: 381-387, 2008.

4. SaintMarcoux B, DeBandt M; CRI (Club Rhumatismes et Inflammation). Vasculitides induced by TNF $\alpha$ antagonists: a study in 39 patients in France. Joint Bone Spine 73: 710-713, 2006.

5. Hirohama D, Hoshino J, Hasegawa E, et al. Development of myeloperoxidase-antineutrophil cytoplasmic antibody-associated renal vasculitis in a patient receiving treatment with anti-tumor necrosis factor- $\alpha$. Mod Rheumatol 20: 602-605, 2010.

6. Sokumbi O, Wetter DA, Makol A, Warrington KJ. Vasculitis associated with tumor necrosis factor- $\alpha$ inhibitors. Mayo Clin Proc 87: 739-745, 2012.

7. Korsten P, Sweiss NJ, Nagorsnik U, et al. Drug-induced granulomatous interstitial nephritis in a patient with ankylosing spondylitis during therapy with adalimumab. Am J Kidney Dis 56: e17e21, 2010.

8. Sugimoto T, Yasuda M, Sakaguchi M, et al. Acute interstitial nephritis associated with etanercept. Rheumatol Int 28: 1283-1284, 2008.

9. Waters AM, Zachos M, Herzenberg AM, Harvey E, Rosenblum ND. Tubulointerstitial nephritis as an extraintestinal manifestation of Crohn's disease. Nat Clin Pract Nephrol 4: 693-697, 2008.
10. Saha MK, Tarek H, Sagar V, Abraham P. Role of tumor necrosis factor inhibitor in granulomatous interstitial nephritis secondary to Crohn's disease. Int Urol Nephrol 46: 229-233, 2014.

11. Chapman JR. Chronic calcineurin inhibitor nephrotoxicity: lest we forget. Am J Transplant 11: 693-697, 2011.

12. Cush JJ. Unusual toxicities with TNF inhibition: heart failure and drug-induced lupus. Clin Exp Rheumatol 22: S141-S147, 2004.

13. Fasanmade AA, Adedokun OJ, Ford J, et al. Population pharmacokinetic analysis of infliximab in patients with ulcerative colitis. Eur J Clin Pharmacol 65: 1211-1228, 2009.

14. Ordás I, Mould DR, Feagan BG, Sandborn WJ. Anti-TNF monoclonal antibodies in inflammatory bowel disease: pharmacokinetics-based dosing paradigms. Clin Pharmacol Ther 91: 635646, 2012.

15. Mavragani CP, Niewold TB, Moutsopoulos NM, Pillemer SR, Wahl SM, Crow MK. Augmented interferon- $\alpha$ pathway activation in patients with Sjögren's syndrome treated with etanercept. Arthritis Rheum 56: 3995-4004, 2007.

16. Dai C, Wang H, Sung SS, et al. Interferon alpha on NZM2328.Lc 1R27: enhancing autoimmunity and immune complex-mediated glomerulonephritis without end stage renal failure. Clin Immunol 154: 66-71, 2014.

(C) 2016 The Japanese Society of Internal Medicine http://www.naika.or.jp/imonline/index.html 